\title{
Guanfacine Treatment of Cognitive Impairment in Schizophrenia
}

\author{
Joseph I. Friedman, M.D., David N. Adler, M.D., Humberto D. Temporini, M.D., \\ Eileen Kemether, M.D., Philip D. Harvey, Ph.D., Leonard White, Ph.D., \\ Michael Parrella, Ph.D., and Kenneth L. Davis, M.D.
}

Norepinephrine plays a significant role in the working memory functions of the prefrontal cortex by its actions at alpha-2a noradrenergic receptors. Guanfacine has demonstrated efficacy in reversing working memory deficits in non-human primate. In the present study the effect of guanfacine adjunctive treatment to neuroleptics on the cognitive performance of schizophrenic patients was investigated in a four week, placebo-controlled, doubleblind, parallel design trial. The primary analyses revealed no significant differences between guanfacine and placebo treatment; however, exploratory non-parametric statistics revealed some significant and some trend differences between guanfacine and placebo on spatial working memory test performance and CPT reaction time in those subjects treated with atypical neuroleptics.

[Neuropsychopharmacology 25:402-409, 2001] (C) 2001 American College of Neuropsychopharmacology. Published by Elsevier Science Inc.
KEY WORDS: Schizophrenia; Norepinephrine; Cognitive; Guanfacine; Clinical Trial

The prefrontal cortex (PFC) is critical for working memory functions and its dysfunction is a source of some of the observed cognitive impairment in schizophrenia (Goldman-Rakic 1987, 1991, 1996). Poor visuospatial working memory performance is characteristic of schizophrenia (Park and Holtzman 1992; Carter et al. 1996; Fleming et al. 1997) and can be related to PFC dysfunction. Multiple catecholamines play a role in the modulation of spatial working memory functions of the PFC including dopamine (Brozoski et al. 1979; Gold-

From the Department of Psychiatry, Mount Sinai School of Medicine, New York, New York (JIF, HDT, EK, PDH, KLD, LW); and the Pilgrim Psychiatric Center, Brentwood, New York (JIF, DNA, MP, LW).

Address correspondence to: Joseph I. Friedman, M.D., Department of Psychiatry, Mount Sinai Hospital, Box 1230, One Gustave L. Levy Place, New York, New York 10029. Tel.: (516) 761-3607; Fax: (516) 761-2718; E-mail: jfriedma@mail.idt.net

Received November 4, 2000; revised February 8, 2001; accepted March 7, 2001.

Online publication: 3/8/01 at www.acnp.org/citations/Npp 03080188 .
man-Rakic et al. 1992; Arnsten et al. 1994) and norepinephrine (Arnsten et al. 1996), the latter being of particular interest.

Young monkeys with noradrenergic-depleting lesions of the PFC are rendered unable to perform a spatial working memory task. Subsequently, alpha-2 noradrenergic agonists like clonidine improve performance on these tasks (Arnsten and Goldman-Rakic 1985), presumably at post-synaptic sites in the prefrontal cortex. Improvements in spatial working memory tasks in aged non-human primates (with naturally occurring decrements of catecholamine activity) can also be achieved with another $\alpha-2$ agonist, guanfacine (Arnsten et al. 1988). The aged nonhuman primates were tested using a two well spatial delayed response task, which measures the process of working memory. The optimal guanfacine dose for improving delayed response performance was $.0016 \mathrm{mg} /$ $\mathrm{kg}$, which was effective within $2 \mathrm{hr}$ after a single intramuscular dose and continued to be effective for 3 to 4 days (Arnsten et al. 1988).

Guanfacine is ten times less potent at lowering blood pressure and 25 times more potent than clonidine at enhancing spatial working memory performance than 
clonidine (Arnsten et al. 1988). The differential cognitive and side effect profiles observed between these two alpha-2 agonists is related to differences in affinities for three alpha-2 noradrenergic receptor subtypes: alpha2A, alpha-2B, and alpha-2C (Kobilka et al. 1987; Regan et al. 1988; Lomasney et al. 1990). The alpha-2B subtype is found predominantly in the thalamus (Nicholas et al. 1993; Scheinin et al. 1994) and mediaties alpha-2 agonists' sedative actions (Buzsaki et al. 1991). The hypotensive effects of alpha-2 agonists are attributable to their actions at alpha-2A and alpha-2C subtypes in the nucleus tractus solitarius (Reis et al. 1984; Nicholas et al. 1993; Scheinin et al. 1994). Immunocytochemical studies in the monkey brain have revealed that the alpha-2A subtype is densest in the PFC (Aoki et al. 1994) and is primarily responsible for the cognitive enhancing effects of alpha-2 agonists. The ability of guanfacine to improve PFC function without significant adverse effects corresponds with its selectivity for the alpha-2A subtype (Uhlen et al. 1995).

Post mortem studies in schizophrenic patients implicate noradrenergic dysfunction in the cognitive impairment observed in these patients. For example, antemortem cognitive impairment correlates with decreases in noradrenergic function at post-mortem examination (Bridge et al. 1985). Schizophrenic subjects classified as demented (Mini Mental Status Examination [MMSE] score less than 20; Folestein et al. 1975) had significantly decreased concentrations of NE in the nucleus accumbens and hypothalamus at post-mortem examination compared to those schizophrenic patients not classified as demented (MMSE > 20) (Bridge et al. 1985). Similar findings were encountered in another post-mortem examination of schizophrenic brain tissue in which NE was significantly reduced in the frontal cortex (Brodmann areas 8, 32, and 44) of schizophrenic patients with significant ante-mortem cognitive impairment compared to schizophrenic patients without such impairment. Therefore, given the possible involvement of noradrenergic dysfunction in the cognitive deficits and its concentration in PFC regions of schizophrenia a reasonable pharmacological strategy for enhancing cognition in these patients is the use of drugs, such as alpha- 2 agonists, which enhance noradrenergic activity in the PFC, and possess only minimal hypotensive properties

Clinical data already supports the efficacy of alpha-2 agonists in some psychiatric disorders. For example, clonidine has been shown to improve PFC mediated cognitive tasks, such as verbal fluency and Stroop test, in patients with Korsakoff's syndrome (patients whose memory loss correlates with NE loss) (Mair and McEntee, 1986; Moffoot et al. 1994), and guanfacine has been shown to improve symptoms of Attention Deficit Hyperactivity Disorder (ADHD) (Chappell et al. 1995; Hunt et al. 1995). Indeed the cognitive enhancing effect of clonidine was linked to its actions in frontal cortex.
Improved performance of the Korsakoff's patients on a verbal fluency test correlated with increased regional cerebral blood flow (rCBF) in the left PFC by singlephoton emission computed tomography imaging (SPECT) (Moffoot et al. 1994). Similarly, guanfacine also shows specificity of action in the PFC in non-human primates (Avery et al. 2000).

Consistent with these data is the reported efficacy of clonidine in improving PFC mediated cognitive functions in schizophrenic patients (Fields et al. 1988). Given these results, it is reasonable to assume that guanfacine, a more selective alpha-2a agonist (Uhlen et al. 1995), will also improve PFC cognitive functions in schizophrenic patients, but with significantly less adverse effects than is seen with clonidine (e.g., sedation, hypotension). An open label pilot study provided preliminary evidence for a cognitive enhancing effect of guanfacine in schizophrenic patients on the trails B taks, a test of frontal cortical function (Friedman et al. 1999). Guanfacine $1 \mathrm{mg}$ per day, administered in conjunction with each subject's neuroleptic treatment for 2 weeks produced a mean improvement of $55 \mathrm{~s}$ on the Trails B task (Friedman et al. 1999). Therefore, a double-blind placebo-controlled trial of guanfacine adjunctive treatment to neuroleptic medication was conducted to test the efficacy of guanfacine in ameliorating some of the cognitive impairment in schizophrenia that has been linked to the frontal cortex.

\section{METHODS}

\section{Subjects}

Forty subjects were recruited from both inpatient and outpatient departments at Mount Sinai Hospital (New York, NY) and Pilgrim Psychiatric Center (Brentwood, NY). All participants met DSM-IV diagnostic criteria for schizophrenia, and no other Axis I or II co-morbid diagnosis. Patients were diagnosed by a senior clinician using the Comprehensive Assessment of Symptoms and History $(\mathrm{CASH})$ structured interview (Andreasen et al. 1992). To be eligible patients had to have been treated with a stable dose of the following neuroleptics for a minimum period of four weeks; haloperidol, fluphenazine, thiothixene, trifluoperazine, or ripseridone. In addition, a minimum of 2 weeks of symptom stability, defined as no more than $20 \%$ change on consecutive ratings on the Positive and Negative Syndrome Scale (PANSS) (Kay 1991), was required for participation in the study. Patients were excluded if they had any medical diagnosis or were receiving medications that may have affected cognitive performance. Furthermore, the following psychotropic medications were not allowed for the duration of the study: anticho- 
linergics, sedating antihistaminics, antidepressants, mood stabilizers, or a second neuroleptic. Finally, subjects were excluded if they had abused alcohol or any illicit drugs within the past 6 months. All patients provided written informed consent in accordance with the procedures outlined by the local institutional review boards of Mount Sinai Hospital and Pilgrim Psychiatric Center prior to participating in the study.

\section{Assessments}

Clinical assessments of psychiatric symptoms were performed with the PANSS (Kay 1991), and extrapyramidal symptoms with the Simpson Angus Scale (Simpson and Angus 1970). The cognitive assessment battery included measures sensitive to frontal lobe dysfunction: Simple Spatial Working Memory Test (McGurk et al. in press), Continuous Performance Test (CPT)-computerized (Cornblatt et al. 1989), and Trail Making Part A \& B (Spreen and Straus 1998). In addition measures of serial verbal learning and delayed recall (Rey Auditory Verbal Learning Test-RAVLT) (Spreen and Strauss 1998), selective attention (Digit Span Distraction Test) (Green et al. 1997), and verbal productivity (Verbal Fluency) (Spreen and Strauss 1998) were used. The Simple Spatial Working Memory Test was developed at the Diagnostic and Psychopathology Unit at UCLA (McGurk et al. in press). This test measures spatial working memory using a computerized delayed response paradigm in which subjects are briefly $(200 \mathrm{~ms})$ exposed to a black circle at one of eight possible target locations arranged in a semi-circle on a computer screen. Subjects are then asked to point to the location of that circle after a 5 or 15 $s$ delay. During the delay subjects engage in a distractor task, which entails the subject counting backwards out loud from a 3 digit number that is displayed on the screen. At the end of the delay eight empty circles appear on the computer screen; these represent the eight possible target locations, and the subject must choose one.

The dependent measure is the number of targets correctly identified at each delay. The Continuous Performance Tests (CPT) is a commonly used test of vigilance. In the identical pairs version of this test (CPT450), subjects are asked to press a computer response key whenever the same target stimulus appears twice in a row. The target stimuli are 90 4-digit numbers presented among 360 4-digit non-target stimuli presented for a 50 ms stimulus duration at a $1000 \mathrm{~ms}$ interstimulus interval.

The Trail Making Tests Part A \& B are tests of visuomotor speed and the ability to set shift. In part A, subjects are asked to connect, as fast as possible, an ascending series of circles containing numbers. In part B, subjects are asked to connect, as fast as possible, an ascending series of circles containing numbers and letters, and subjects are asked to alternate between the numbers and let- ters. The RAVLT is a test of immediate memory span, new learning, susceptibility to interference, and recognition memory (Spreen and Strauss 1998). The test contains 15 target words (List A), which are read aloud in five separate learning trials, with each trial followed by a free-recall test. Following trial 5, an interference list of 15 words (List B) is presented followed by a free recall test of that list. Immediately after, delayed recall of the first list (List A) is tested. After a 20 min delay period the subject is required to recall words from List $\mathrm{A}$. The dependent measures include indices of concentration measured by word span (trial 1 performance), cumulative practice-related learning (the difference of learning trial 5 and learning trial 1), and delayed recall savings (trial 5 performance minus delayed recall).

The Digit Span Distraction Test is a commonly used test of memory span and distraction. There are two conditions in this test: distraction and non-distraction. In the non-distraction condition six digits per trial are read in a female voice and the subjects are instructed to recall the digits in order after each trial. Under the distraction condition, a male voice reads four irrelevant digits between the presentation of each of the five target digits read by the female voice. Subjects are instructed to attend to the female voice, ignoring anything they hear from the male voice, and recall the digits in order. Each trial is scored for the number of digits recalled correctly. Verbal fluency tests measure verbal productivity and the intactness of the lexical system. In this protocol, the category fluency test was administered. Subjects were asked to produce the names of as many different animals within a one min period. The number of original words that belonged in that category is the dependent measure.

\section{Study Design}

Following baseline assessments, subjects entered a 4-week, double-blind, parallel design treatment phase during which they were randomly assigned to receive either $2 \mathrm{mg}$ of guanfacine daily (in two divided doses) or placebo in addition to neuroleptic treatment. The dose of guanfacine was titrated from $0.5 \mathrm{mg}$ daily to $2 \mathrm{mg}$ daily over the first ten days and then continued at this dose for the remainder of the 4-week, double-blind treatment phase. This dose of guanfacine was chosen on the basis of a modest cognitive effect associated with the $1 \mathrm{mg}$ dose used in the open label trial with schizophrenic patients (Friedman et al. 1999) and the possibility of a larger effect with higher doses. Although a mean therapeutic dose of guanfacine of $3.2 \mathrm{mg}$ per day produced significant improvements in patients with ADHD (Hunt et al. 1995), the increase from $2 \mathrm{mg}$ to $3 \mathrm{mg}$ per day is associated with a greater incremental increase in incidence of side effects than is the increase from $1 \mathrm{mg}$ to $2 \mathrm{mg}$ (Physicians Desk Reference 2000). For example, the prevalence of 
Table 1. Subject Characteristics by Treatment Arm

\begin{tabular}{lrlccc}
\hline Treatment & N & Age & $\begin{array}{c}\text { Illness } \\
\text { Duration }\end{array}$ & $\begin{array}{c}\text { \% } \\
\text { Male }\end{array}$ & $\begin{array}{c}\text { Baseline } \\
\text { Mmse }\end{array}$ \\
\hline $\begin{array}{l}\text { Typicals + placebo } \\
\text { Typicals + guanfacine }\end{array}$ & 9 & 51.2 & 27.5 & 67 & 28.3 \\
$\begin{array}{l}\text { Risperidone + placebo } \\
\begin{array}{l}\text { Risperidone + } \\
\quad\end{array}\end{array}$ & 11 & 44.1 & 21.6 & 91 & 27.4 \\
$\quad$ guanfacine & 11 & 46.3 & 23 & 81 & 25.7 \\
\hline
\end{tabular}

somnolence associated with the $1 \mathrm{mg}, 2 \mathrm{mg}$, and $3 \mathrm{mg}$ dose is $0 \%, 1 \%$, and $14 \%$ respectively (Physicians Desk Reference). Therefore the dose of $2 \mathrm{mg}$ per day was chosen in an attempt to optimize the risk to benefit ratio. Furthermore, the titration dose used was adopted from the open label study in patients with ADHD in which the tolerability of this titration schedule was demonstrated (Hunt et al. 1995). The clinical assessment battery as well as monitoring of vital signs and adverse drug effects was performed at baseline and weekly thereafter. The cognitive assessment battery was performed at baseline and at week 4 only.

\section{Analyses}

Baseline comparisons between groups were performed using $t$ tests for continuous variables and chi square for categorical variables. Guanfacine's comparative efficacy to placebo was analyzed with Analysis of Variance (ANOVA) comparing change scores from baseline to week 4 on cognitive tests between the groups receiving guanfacine and the group receiving placebo. The alpha significance for these tests was set to a level of .05. Subjects completing week 1 clinical assessments were considered to be evaluable for efficacy analysis.

\section{RESULTS}

Forty patients entered the study and thirty-nine patients were randomized (guanfacine $\mathrm{N}=19$, placebo $\mathrm{N}=$ 20). Thirty-eight patients completed the entire protocol. One subject dropped prior to randomization, and one subject receiving placebo was terminated during week 2 of treatment because of noncompliance with neuroleptic and study medication. Pertinent baseline data for subjects included in endpoint analysis is: mean age $=$ $47.3(\mathrm{sd}=10.4)($ placebo $)$ and 49.1 years $(\mathrm{sd}=11)($ guanfacine), mean duration of illness $=24.4$ years $(\mathrm{sd}=$ 13.2)(placebo) and 26.2 years $(\mathrm{sd}=13)$ (guanfacine), baseline Mini Mental State Examination score $=27.8$ $(\mathrm{sd}=2)($ placebo $)$ and 26.2(sd $=3.5)($ guanfacine $)$. The distribution of neuroleptic treatment for the two randomized guanfacine groups were as follows: placebo ( $45 \%$ typicals, $55 \%$ risperidone) and guanfacine $(42 \%$ typicals, $58 \%$ risperidone). The guanfacine and placebo treated groups did not differ significantly by $\mathrm{t}$ test and chi square analysis on any of the baseline demographic or treatment variables.

There were no statistically significant differences in change scores (from baseline to week 4) on any of the

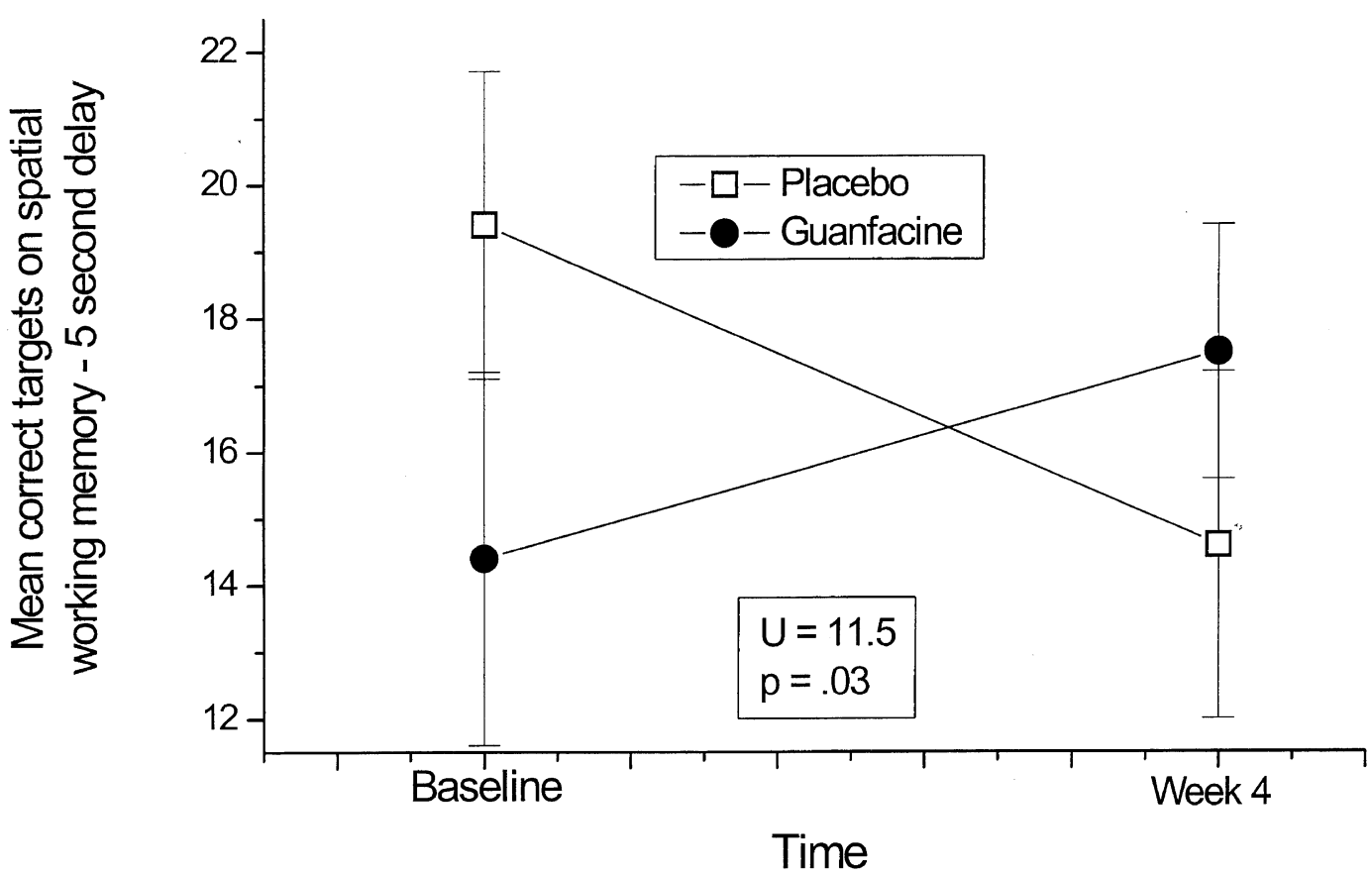

Figure 1. Guanfacine vs. placebo on spatial working memory performance at $5 \mathrm{~s}$ delay in risperidone treated patients only. 
cognitive measures between the placebo and guanfacine treated groups. Given the possibility that the dopaminergic activity inherent in some typical neuroleptics (e.g., D1 antagonism) could adversely effect cognition and therefore counter the putative benefits of guanfacine, we conducted a subsequent exploratory post-hoc analysis of the effect of guanfacine in the ripseridone treated subjects. Fifty percent of the patients receiving risperidone $(\mathrm{N}=11)$ were randomized to treatment with guanfacine. Baseline characteristics for patients grouped on the basis of neuroleptic and study drug treatment are shown in Table 1. Given that the data in these groups was not normally distributed and that the sample size in each group was limited $(\mathrm{N}<10$ of evaluable data), non-parametric statistics were used in the exploratory analyses. The Mann Whitney U test was used to assess the significance of the differences in cognitive test change scores between the guanfacine and placebo treated subjects receiving risperidone.

The combination of risperidone and guanfacine produced improvement in spatial working memory performance, reaction time on the CPT, and Trails B performance. The mean improvement of 3.1 correct targets on the $5 \mathrm{~s}$ delay of the spatial working memory test for the risperidone + guanfacine treated group was significantly greater than that for the placebo group $(\mathrm{U}=11.5$, $p=.03$ ) (Figure 1). The mean improvement of 3 correct target locations at the $15 \mathrm{~s}$ delay for the guanfacine + risperidone group showed a trend difference from the placebo + risperidone group $(\mathrm{U}=18, p=.14)$ (Figure 2). In addition, the mean $55 \mathrm{~ms}$ improvement in CPT re- action time for the risperidone + guanfacine group showed a trend difference from the placebo + risperidone group ( $\mathrm{U}=12, p=.1$ ) (Figure 3). While the combination of risperidone and guanfacine produced an improvement of 5 words on serial learning and 1.5 words on delayed recall from the RAVLT, and a mean $40 \mathrm{~s}$ improvement on the Trails B test, these improvements were not different in magnitude from that associated with the risperidone and placebo combination. Finally, no improvement on verbal fluency or digit span distraction test performance was associated with the guanfacine and risperidone combination.

It is also important to note that the addition of guanfacine to either risperidone or typical neuroleptics produced no significant change in positive or negative symptoms as measured by the PANSS. As well, guanfacine did not significantly influence the severity of extrapyramidal symptoms as measured by the SimpsonAngus rating scale (Simpson and Angus 1970). While there was a slight decrease in systolic blood pressure in the guanfacine treated group from a mean of $121.4 \mathrm{~mm}$ $\mathrm{Hg}$ to $115 \mathrm{~mm} \mathrm{Hg}$, this was not statistically different from placebo.

\section{CONCLUSIONS}

The a priori efficacy hypothesis for guanfacine on cognitive symptoms in schizophrenic patients was not supported by the primary analyses conducted in this study. This may have been a consequence of the differential ef-

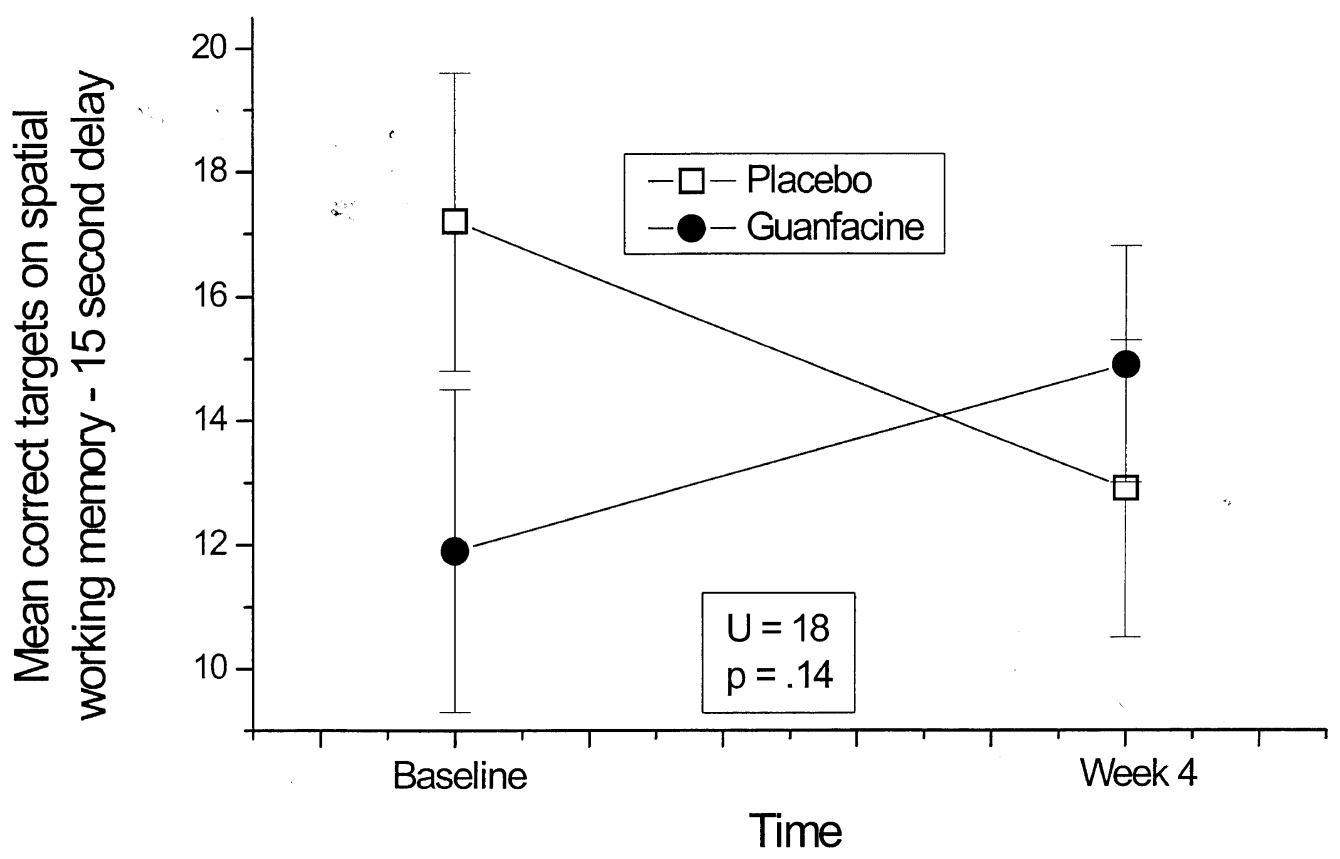

Figure 2. Guanfacine vs. placebo on spatial working memory performance at $15 \mathrm{~s}$ delay in risperidone treated patients only. 


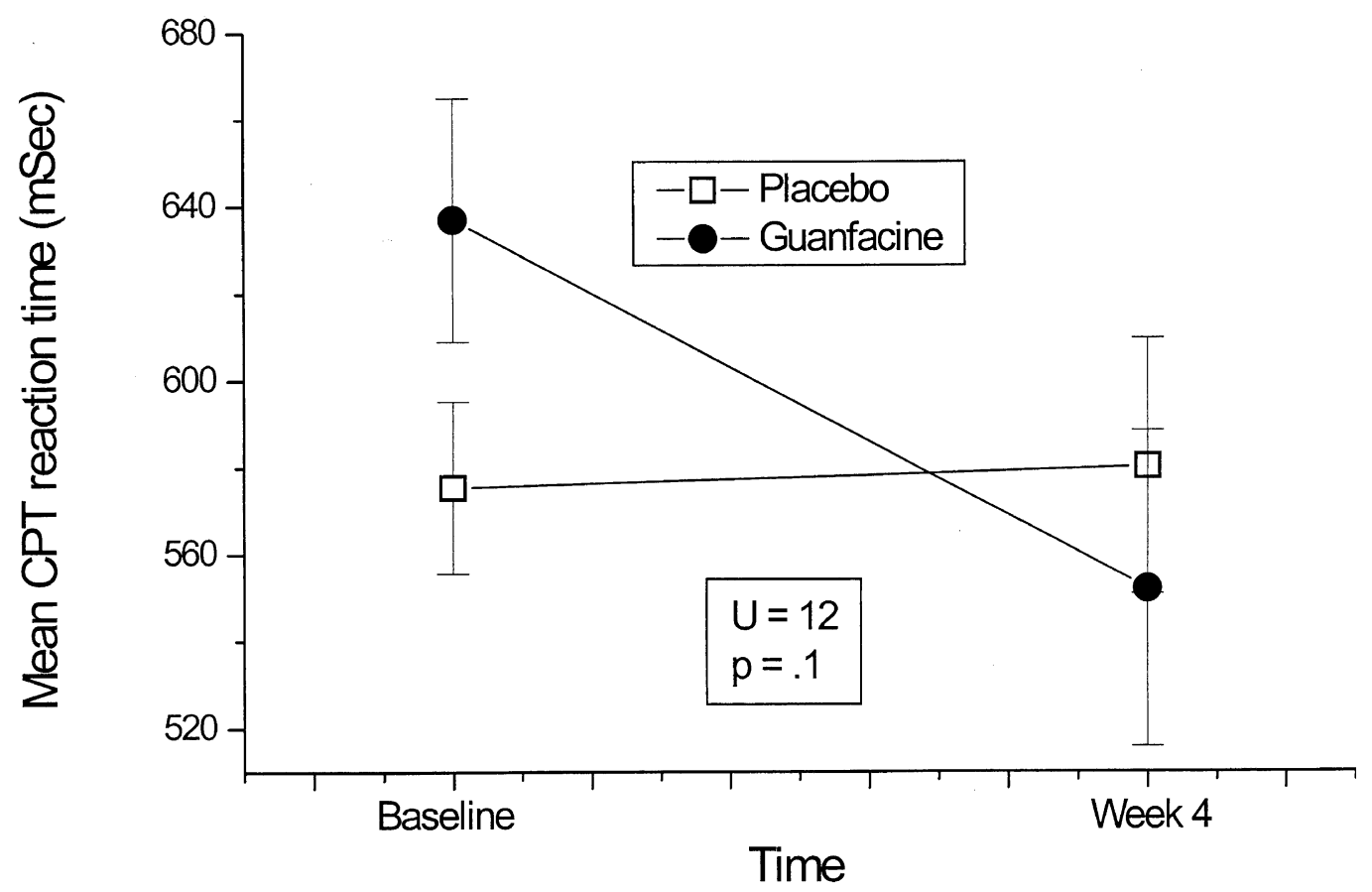

Figure 3. Guanfacine vs. placebo on CPT reaction time in risperidone treated patients only.

fects of typical and atypical neuroleptics on catecholamine release in the PFC in the context of the notion that the PFC functions optimally under conditions of both moderate dopamine activity at D1 dopamine receptors and moderate norepinephrine activity at alpha-2 noradrenergic receptors (reviewed by Arnsten 1998). The apparent window for optimal effects of these catecholamines upon cognitive functioning is relatively narrow, with both increases or decreases above the optimal range leading to poor performance. Indeed, indices of low mesocortical dopamine activity in schizophrenic patients are associated with poor performance on neuropsychological tasks dependent upon PFC function (e.g., visuospatial memory and executive function) (Berman et al., 1988; Kahn et al. 1994; Okubo et al. 1997). Therefore, it is conceivable that a low state of cortical dopamine activity in schizophrenic patients (Davis et al. 1991) would need to be addressed, perhaps with an atypical neuroleptic, before the beneficial effects of an alpha- 2 agonist could be achieved. In fact, chronic administration of the typical neuroleptic haloperidol produces impairments in working memory functions of non-human primates not associated with any effects on motor components required to perform these tasks (Castner et al. 2000). Subsequently, the co-administration of a D1 agonist produces sustained improvement in the working memory performance of these animals (Castner et al. 2000). Perhaps differences in direct actions between haloperidol and atypical neuroleptics (which produce higher concentrations of extracellular DA in the PFC) in the PFC may explain the permissive effects of risperidone on guanfacine's ability to improve working memory (Gessa et al. 2000). However, this is only speculative given that the aforementioned experiment compared haloperidol to clozapine and olanzapine, but not risperidone (Gessa et al. 2000). Given this possibility though, exploratory analyses were conducted which revealed some significant and some trend differences for the guanfacine effect on cognition compared to placebo in risperidone treated subjects

The results of the exploratory analyses are suggestive of a cognitive enhancing effect of guanfacine adjunctive treatment to risperidone restricted to measures subsumed by frontal lobe function (e.g., spatial working memory, vigilance). This is consistent with other data demonstrating the ability of alpha- 2 agonists to improve cognitive functions dependent upon dorsolateral (Avery et al. 2000) and ventromedial orbital (Steere and Arnsten 1997) PFC function, but not cognitive functions dependent on other brain areas (e.g., hippocampus, inferomedial temporal lobe)(Sirvio et al. 1991; Jakala et al. 1999). Although performance on the spatial working memory test (Arnsten and Goldman-Rakic 1985; Avery et al. 2000; has been clearly linked to the integrity of frontal lobe functions, it may be argued that the improvement in performance on CPT reaction time observed in this study was related to guanfacine's effect on psychomotor speed and not a change in frontal lobe function. However, neuroimaging has correlated poor CPT performance with reduced frontal activity in schizophrenic 
patients (Buchsbaum et al. 1990; Volz et al. 1999). In addition, reaction tine performance on the CPT has been validated as an index of attention (Reinvang 1998). Finally, no significant change in Trail Making Part A was seen. Because part A measures psychomotor speed, the effect of guanfacine on CPT reaction time appears consistent with a vigilance effect and not a generalized effect of speed.

These results are limited because the analyses of guanfacine's effects in combination with risperidone are only exploratory and post hoc in nature. Furthermore, the analyses revealed only one statistically significant and two trend differences in cognitive test change scores between the guanfacine and placebo treated subjects receiving risperidone. However, they do warrant further investigation with a prospective double-blind, placebo-controlled trial of guanfacine in patients being treated with risperidone. Additionally, the dosage of guanfacine used in this study may have been sub-optimal; therefore other dosages should be investigated as well. Should the results of such a study support the hypothesis of a cognitive enhancing effect of guanfacine in schizophrenia then the question of the generalizability of guanfacine's effect to other atypical neuroleptics should be addressed.

\section{REFERENCES}

Andreasen NC, Flaum M, Arndt S (1992): The Comprehensive Assessment of Symptoms and History (CASH). An instrument for assessing diagnosis and psychopathology. Arch Gen Psychiatry 1992 49:615-623

Aoki C, Go CG, Venkatesan C, Kurose H (1994): Perikaryal and synaptic localization of alpha 2A-adrenergic receptor-like immunoreactivity. Brain Res 650(2):181-204

Arnsten AFT (1998): Catecholamine modulation of prefrontal cortical cognitive function. Trends Cog Sci 2:436-447

Arnsten AFT, Cai JX, Goldman-Rakic PS (1988): The alpha-2 adrenergic agonist guanfacine improves memory in aged monkeys without sedative or hypotensive side effects: Evidence for alpha-2 receptor subtypes. J Neurosci 8:4287-4297

Arnsten AFT, Cai JX, Murphy BL, Goldman-Rakic PS (1994): Dopamine D1 receptor mechanisms in the cognitive performance of young adult and aged monkeys. Psychopharmacology 116:143-151

Arnsten AF, Steere JC, Hunt RD (1996): The contribution of alpha 2-noradrenergic mechanisms of prefrontal cortical cognitive function potential significance for attention-deficit hyperactivity disorder. Arch Gen Psychiatry 53:448-455

Arnsten AFT, Goldman-Rakic PS (1985): Alpha-2 adrenergic mechanisms in prefrontal cortex associated with cognitive decline in aged non-human primates. Science 230: 1273-1276

Avery RA, Franowicz JS, Studholme C, van Dyck CH, Arnsten AFT (2000): The alpha-2a-adrenoreceptor agonist, guanfacine, increases regional cerebral blood flow in dorsolateral prefrontal cortex of monkeys performing a spatial working memory task. Neuropsychopharmacology 23:240-249

Berman KF, Illowsky BP, Weinberger DR (1988): Physiological dysfunction of dorsolateral prefrontal cortex in schizophrenia: IV. Further evidence for regional and behavioral specificity. Arch Gen Psychiatry 45:616-622

Bridge TP, Kleinman JE, Karoum F, Wyatt RJ (1985): Postmortem central catecholamines and ante mortem cognitive impairment in elderly schizophrenics and controls. Biol Psychiatry 14:57-61

Brozoski T, Brown R, Rosvold H, Goldman P (1979): Cognitive deficit caused by regional depletion of dopamine in prefrontal cortex of rhesus monkeys. Science 205:929-932

Buchsbaum MS, Nuechterlein KH, Haier RJ, Wu J, Sicotte N, Hazlett E, Asarnow R, Potkin S, Guich S (1990): Glucose metabolic rate in normals and schizophrenics during the Continuous Performance Test assessed by positron emission tomography. Br J Psychiatry 156:216-227

Buzsaki G, Kennedy B, Solt VB, Ziegler M (1991): Noradrenergic control of thalamic oscillation: the role of alpha-2 receptors. Eur J Pharmacol 3:222-229

Carter C, Robertson L, Nordahl T, Chaderjian M, Kraft L, O'Shora-Celaya L (1996): Spatial working memory deficitsand their relationship to negative symptoms in unmedicated schizophrenia patients. Bio Psychiatry 40:930-932

Castner SA, Williams GV, Goldman-Rakic PS (2000): Reversal of antipsychotic-induced working memory deficits by short-term dopamine D1 receptor stimulation. Science 287:2020-2022

Chappell PB, Riddle MA, Seahill L, Lynch KA, Schultz R, Arnsten A, Leckman JF, Cohen DJ (1995): Guanfacine treatment of comorbid attention deficit hyperactivity disorder and Tourette's syndrome: Preliminary clinical experience. J Am Acad Child Adolesc Psychiatry 34:1140-1146

Cornblatt BA, Lenzenweger MF, Erlenmeyer-Kimling L (1989): The continuous performance test, identical pairs version: II. Contrasting attentional profiles in schizophrenic and depressed patients. Psychiatry Res 29:65-85

Davis KL, Kahn RS, Ko G, Davidson M. (1991): Dopamine in schizophrenia: a review and reconceptualization. Am J Psychiatry 148:1474-1486

Fields RB, van Kammen DP, Peters JL, Rosen J, van Kammen WB, Nugent A, Stipetic M, Linnoila M (1988): Clonidine improves memory function in schizophrenia independently from changes in psychosis: preliminary findings. Schizophrenia Research 1:417-423

Fleming K, Goldberg T, Binks S, Randolph C, Gold J, Weinberger D (1997): Visuospatial working memory in patients with schizophrenia. Bio Psychiatry 41:43-43

Friedman JI, Adler DN, Davis KL (1999): The role of norepinephrine in the pathophysiology of cognitive disorders: Potential applications to the treatment of cognitive dysfunction in schizophrenia and Alzheimer's disease. Biol Psychiatry 46:1243-1252

Gessa GL, Devoto P, Diana M, Flore G, Melis M, Pistis M (2000): Dissociation of haloperidol, clozapine, and olanzapine effects on electrical activity of mesocortical dopamine neurons and dopamine release in the prefrontal cortex. Neuropsychopharmacology 22:642-649 
Goldman-Rakic P (1996): Regional and cellular fractionation of working memory. Proc Nat Acad Sci USA 93:1347313480

Goldman-Rakic P (1991): Prefrontal cortical dysfunction in schizophrenia: the relevance of working memory. In Carroll BJ, Barrett JE (eds), Psychopathology and the Brain. New York, Raven Press, pp 1-23

Goldman-Rakic PS (1987): Circuitry of the primate prefrontal cortex and the regulation of behavior by representational memory. In Plum F (ed), Handbook of Physiology: The Nervous System, Higher Function of the Brain. Bethesda MD, American Physiological Society

Goldman-Rakic PS, Lidow MS, Smiley JF, Williams MS (1992): The anatomy of dopamine in monkey and human prefrontal cortex. J Neural Transm Suppl 36: 163-177

Green MF, Marshall BD Jr, Wirshing WC, Ames D, Marder SR, McGurk S, Kern RS, Mintz J (1997): Does risperidone improve verbal working memory in treatment resistant schizophrenia? Am J Psychiatry 154:799-804

Hunt RD, Arnsten AFT, Asbell MD (1995): An open trial of guanfacine in the treatment of attention deficit hyperactivity disorder. J Am Acad Child Adolesc Psychiatry 34:50-54

Jakala P, Sirvio J, Riekkinen M, Koivisto E, Kejonen K, Vanhanen M, Riekkinen P (1999): Guanfacine and clonidine, alpha-2 agonists, improve paired associates learning, but not delayed matching to sample, in humans. Neuropsychopharmacology 20:119-130

Kahn R, Harvey P, Davidson M, Keefe R, Apter S, Neale J et al (1994): Neuropsychological correlates of central monoamine function chronic schizophrenia: relationship between CSF metabolites and cognitive function. Schizophr Res 11:217-224

Kay, S.R. (1991): Positive and Negative Syndromes in Schizophrenia. New York, Brunner/Mazel

Kobilka BK, Matsui H, Kobilka TS, Yang-Feng TL, Caron MG, Lefkowitz RJ, Regan JW (1987): Cloning and sequencing, and expression of the gene coding for the human platelet alpha-2 adrenergic receptor. Science 238:650-656

Lomasney JW, Lorenz W, Allen LF, King K, Regan JW, YangFeng TL, Caron M, Lefkowitz RJ, Fremeau RT (1990): Expansion of the a-2 adrenergic family: cloning and characterization of human a-2 adrenergic subtype, the gene for which is located on chromosome 2. Proc Natl Acad Sci USA 87:5094-5098

Mair RG, McEntee WJ (1986): Cognitive enhancement in Korsakoff's psychosis by clonidine: A comparison with L-Dopa and ephedrine. Psychopharmacol 88:374-380

McGurk SR, Green MF, Wirshing WC, Wirshing DA, Marshall BD, Marder SR, Kern R, Mintz J: Pharmacological evaluation of spatial memory in schizophrenia. J Clin Exp Neuropsychol, in press

Moffoot A, O'Carroll RE, Murray C, Dougall N, Ebmeier K,
Goodwin GM (1994): Clonidine infusion increases uptake of $99 \mathrm{mTc}$-Exametazime in anterior cingulate cortex in Korsakoff's psychosis. Pschol Med 24:53-61

Nicholas AP, Pieribone V, Hokfelt T (1993): Distribution of mRNA's for a-2 adrenergic receptor subtypes in rat brain: an in situ hybridization study. J Comp Neurol 328:575-594

Okubo Y, Suhara T, Suzuki K, Kobayashi K, Inoue O, Terasaki O et al (1997): Decreased prefrontal dopamine D1 receptors in schizophrenia revealed by PET. Nature 385:634-636

Park S, Holtzman P (1992): Schizophrenics show spatial working memory deficits. Arch Gen Psychiatry 49:975-982

Physicians Desk Reference (54th ed.) (2000): Montvale, NJ, Medical Economics

Regan JW, Kobilka TS, Yang Feng TL, Caron MG, Lefkowitz RJ, Kobilka BK (1988): Cloning and expression of a human kidney cDNA for an a-2 adrenergic receptor subtype. Proc Natl Acad Sci USA 85:6301-6305

Reinvang I (1998): Validation of reaction time in continuous performance tasks as an index of attention by electrophysiological measures. J Clin Exp Neuropsychol 20:885-897

Reis DJ, Granata AR, Joh TH, Ross CA, Ruggiero DA, Park DH (1984): Brain stem catecholamine mechanisms in tonic and reflex control of blood pressure. Hypertension 6(S11):7-15

Scheinin M, Lomasney JW, Hayden-Hixson DM, Schambra UB, Caron MG, Lefkowitz RJ, Femeau RT (1994): Distribution of a-2 adrenergic receptor subtype gene expression in rat brain. Mol Brain Res 21:133-149

Simpson GM, Angus JWS (1970): A rating scale for extrapyramidal side effects. Acta Psychiatry Scand 212:11-19

Sirvio J, Riekkinen P Jr, Vajanto I, Koivisto E, Riekkinen PJ (1991): The effects of guanfacine, alpha-2 agonist, on the performance of young and aged rats in spatial navigation task. Behav Neural Bio 56:101-107

Spreen O, Strauss E (1998): A Compendium of Neuropsychological Tests and Norms (2nd ed.). New York, Oxford University Press

Steere JC, Arnsten AFT (1997): The alpha-2A noradrenergic agonist, guanfacine, improves visual object discrimination reversal performance in rhesus monkeys. Behav Neurosci 111:1-9

Uhlen S, Muceniece R, Rangel N, Tiger G, Wilberg J (1995): Comparison of the binding activities of some drugs on a-2A, A-2B, a-2C adrenoreceptors in noradrenergic imidazoline sites in the guinea pig. Pharmacology and Toxicology 76:353-364

Volz H, Gaser C, Hager F, Rzanny R, Ponisch J, Mentzel H, Kaiser WA, Sauer H (1999): Decreased frontal activation in schizophrenics during stimulation with the continuous performance test-afunctional magnetic resonance imaging study. Eur Psychiatry 14:17-24 